This is an electronic reprint of the original article. This reprint may differ from the original in pagination and typographic detail.

Author(s): Lahti, Malgorzata

Title: $\quad$ Sharing cultural knowledge at work: a study of chat interactions of an internationally dispersed team

Year: $\quad 2015$

Version:

Please cite the original version:

Lahti, M. (2015). Sharing cultural knowledge at work: a study of chat interactions of an internationally dispersed team. Language and Intercultural Communication, 15(4), 513-532. https://doi.org/10.1080/14708477.2015.1031673

All material supplied via JYX is protected by copyright and other intellectual property rights, and duplication or sale of all or part of any of the repository collections is not permitted, except that material may be duplicated by you for your research use or educational purposes in electronic or print form. You must obtain permission for any other use. Electronic or print copies may not be offered, whether for sale or otherwise to anyone who is not an authorised user. 
Lahti, M. (2015). Sharing cultural knowledge at work: A study of chat interactions of an internationally dispersed team. Language and Intercultural Communication, 15(4), 513-532. doi: 10.1080/14708477.2015.1031673

\title{
Sharing cultural knowledge at work: A study of chat interactions of an internationally dispersed team
}

\author{
Malgorzata Lahti \\ Department of Communication, University of Jyvaskyla, Jyvaskyla, Finland
}

\author{
Department of Communication \\ P.O. Box 35 \\ FI-40014 University of Jyvaskyla \\ Finland \\ Phone: +358445218 742 \\ E-mail: malgorzata.lahti@jyu.fi
}

\begin{abstract}
In this study the ethnomethodological method of membership categorisation analysis is applied to examine how members of an internationally dispersed team share cultural knowledge in their Skype ${ }^{\mathrm{TM}}$ chat conversations through mobilising categorisation as 'cultural knower' and 'not knower' for oneself and the others. Four recurring ways of sharing cultural knowledge were identified as the participants managed the distribution and completion of tasks, and attended to building mutual understanding in the unfolding interaction. The findings illustrate that cultural knowledge sharing is dynamic, situational and collaborative. Rather than hindering or enhancing interaction, culture is an interactional accomplishment with fluid referents, boundaries and membership. These observations problematise the predominant accounts of internationally dispersed teaming as either fraught with intercultural misunderstanding and conflict, or brimming with innovation and synergy.
\end{abstract}

\section{Keywords}

cultural knowledge sharing, internationally dispersed teams, membership categorisation analysis, workplace interactions

\section{Introduction}

Organisations have entered a new era characterised by the intensification of such trends as globalisation of the marketplace, corporate restructuring, flexible work arrangements and proliferation of advanced communication technologies (Chrobot-Mason, Ruderman, \& Nishii, 2013; Gibbs, Nekrassova, Grushina, \& Wahab, 2008). These transformations have led to the rise of internationally dispersed teams whose members, rather than sharing a geographical site and working face-to-face, are located in different countries and collaborate primarily in technology-mediated ways (e.g. Scott, 2013). As critical operating units in increasingly complex and interconnected business environments, internationally distributed teams have been considered central nodes for knowledge sharing in organisations (Baba, Gluesing, Ratner, \& Wagner, 2004).

This article focuses on the sharing of knowledge pertaining to location-specific group-based meanings, symbols and practices, or cultural knowledge (see also Collier \& Thomas, 1988), which may be especially relevant in the context of internationally dispersed collaboration. Internationally dispersed teamwork creates spaces where individuals from 
different cultural backgrounds come into contact with one another to share tasks and goals (Gibbs et al., 2008). Team members may have different information, expectations, preferences and constraints resulting from their embeddedness in diverse contexts (Cramton $\&$ Hinds, 2005). To collaborate successfully, they need to establish shared frames of reference that ensure similar interpretations of situations they face as a team (Gibson \& Gibbs, 2006). Moreover, internationally dispersed teams may explicitly rely on cultural knowledge sharing as they are often formed with a view to enhancing the organisational understanding of local markets and encouraging innovation (Scott, 2013). Although these themes have inspired intense research interest, the burgeoning literature has tended to take a post-positivistic approach that focuses on mapping the antecedents and outcomes of team processes, and conceptualises culture and communication as variables (see also Connaughton \& Shuffler, 2007; Gibbs et al., 2008). In the light of this, the very process of cultural knowledge sharing that team members engage in as their everyday interactions unfold has remained largely unexplored.

In this article, I argue that our understanding of how cultural knowledge is shared in internationally dispersed teamwork can be deepened by a detailed inductive exploration of naturally occurring interactions of an ongoing working life team. This study draws on records of Skype ${ }^{\mathrm{TM}}$ chat conversations of a Finnish-Russian team whose members were located in Finland and Russia, were native speakers of either Finnish or Russian respectively, and who dealt in the internationalisation of Finnish companies onto Russian markets. Utilising the ethnomethodological framework of membership categorisation analysis (MCA) (e.g. Lepper, 2000; Sacks, 1986), this study seeks to identify and describe the systematic and commonsensical ways in which the participants share cultural knowledge in interaction through mobilising categorisation as 'cultural knower' and 'not knower' for oneself and the other(s).

\section{Cultural knowledge sharing in internationally dispersed teamwork}

Technology-mediated teamwork that spans national boundaries is a unique contemporary phenomenon enabled by fairly recent economic, technological, cultural and political developments associated with globalisation. To unravel the complexities of internationally dispersed teamwork, researchers have mostly relied on post-positivistic theorising developed in the context of more traditional face-to-face culturally diverse groups and teams, adding virtuality as an additional variable.

Within the post-positivistic perspective, culture is approached as an objectively existing fact tied to a nation-state or ethnicity (in some cases, also 'race' has been used an apparent substitute for ethnicity) that affects team processes. To explain and predict the influence of culture, researchers have relied on the theoretical frameworks of information and decision-making, and social identity and categorisation (see also Stahl, Maznevski, Voigt, \& Jonsen, 2010 for a review). The information and decision-making perspective examines how differences associated with individual members' culturally shaped values, knowledge, skills and perspectives hinder or enhance team performance in terms of achieving shared understanding, problem solving or innovation. The social identity and categorisation framework considers different cultural memberships as triggering the formation of subgroups that prevents individuals from developing relationships and sharing information with members of the perceived outgroup. These tendencies are seen as intensified with virtuality added to the picture (see e.g. Berry, 2011; Connaughton \& Shuffler, 2007 for reviews). As the argument goes, cultural diversity among team members and a high degree of dependence on communication technologies for interaction combine to work as a 'double-edged sword', leading to either impaired knowledge processing or innovation. 
The joint negative effects of virtuality and unacknowledged and unshared cultural knowledge on team efficiency have received ample attention. As was found in a study utilising data from teams of undergraduate students from the US and Thailand collaborating on a project, virtuality may aggravate problems related to divergent national preferences for social interaction and poor language skills in the lingua franca (Sarker, 2005). The constraints of technology-mediated interaction may also result in undermined sharing of tacit contextual knowledge about local ways of work and life, resulting in misinterpretations of one's remote colleagues' motives and conduct (Cramton, 2001; Zakaria, Amelinckx, \& Wilemon, 2004). In their theoretical discussion of internationally distributed team dynamics, Cramton and Hinds (2005) proposed that such teams are prone to the formation of subgroups along the cultural and geographic faultlines, encouraging ethnocentric perceptions of outgroup members. Indeed, a survey- and interview-based comparative study conducted in a multinational organisation that had both dispersed and traditional teams found that dispersed teams experienced more conflict (Hinds \& Mortensen, 2005).

Conversely, scholars have also looked into factors promoting processes that entail cultural knowledge actually being shared and that have been associated with the purported benefits of cultural team diversity, such as intercultural learning or innovation. For instance, Cramton and Hinds (2005) suggested that an attitude of 'positive mutual distinctiveness' could be a mediating variable encouraging ethnorelativistic learning where subgroups learn from and about one another's culture and local situation, enabling the team to capitalise on intergroup differences. This claim received support from a large-scale interview study by Gibson and Gibbs (2006) that identified a positive relationship between supportive communicative climate, a perception of national team diversity as an asset, and innovation. It has also been suggested that the negative effects of social categorisation processes may be mitigated by communication technologies. Building on data from undergraduate student project work, Berg (2012) argued that the reduced social context cues in technology-mediated interactions alleviated stereotyping and intergroup bias common to face-to-face intercultural interactions, encouraging the sharing of deep-seated cultural resources.

Although existing literature has offered some important insights into the conditions and outcomes of the sharing (or not sharing) of cultural knowledge, it suffers from a number of limitations. Adherence to the 'double-edged sword' theorising reduces our understanding of internationally dispersed teaming to only two scenarios where it is framed as either an organisational asset or a hindrance (see also Stahl et al., 2010). In empirical investigations, this is coupled with excessive reliance on induced data gathered through interviews, surveys and experiments that often utilise student subjects or artificial zerohistory teams. Such research designs yield only indirect insights into the actual patterns of team interaction in real working life. The very dynamics of knowledge work, often referred to as the 'black box' of team processes, have remained largely unexplored (Erhardt \& Gibbs, 2008). Most importantly, research tends to draw on a limited conceptualisation of the relationship between culture and communication (see also Connaughton \& Shuffler, 2007; Gibbs et al., 2008). Culture is relegated to the position of a finite, static and distinctive set of experiences, perceptions, values, behaviours and skills that is a natural property of a national or ethnic group. This system of traits is seen as unproblematically shared by all group members, determining what they know and how they communicate. Interactions of internationally distributed teams are therefore treated as either ridden with intercultural misunderstandings and conflict, or brimming with cultural innovation and learning, simply by virtue of team members' different national/ethnic backgrounds.

The post-positivistic conceptualisation of culture has recently received intense criticism in fields such as intercultural communication, anthropology or sociolinguistics for 
oversimplifying and decontextualising human interaction, offering distorted explanations and predictions about the workings of the social world, sanctioning stereotypes about groups, and ignoring the processes triggered by globalisation (e.g. Breidenbach \& Nyíri, 2009; Dervin, 2014; Holliday, 2011; Rubdy \& Alsagoff, 2014). As Breidenbach and Nyíri (2009) have remarked, the predominant understanding of culture has led to the development of two contradictory discourses where cultural difference is either uncritically celebrated or pathologised. They argue that such images do not correspond with people's lived realities. Nation and ethnicity are too large to be real groups and it is more adequate to treat them as imagined communities (Piller, 2011). Both cultural identity and culture are open-ended and fluid; individuals do not exist within the tight confines of some immutable homogeneous communities but dynamically construe their ways of life, aspirations and knowledge of the social world through interactions with myriad different groups and ideas enabled, for instance, by travel or access to media and technologies (Hunsinger, 2006). The intensification of cultural interconnectedness brought on by globalisation has undermined the tie between culture and physical place, giving rise to new forms of social interaction that necessitate a rethinking of traditional scientific concepts and methods of inquiry (Rubdy \& Alsagoff, 2014). Rather than mapping cultural traits possessed and passively inherited by members of national or ethnic groups, researchers should be asking when and why culture may be made relevant by social actors (Piller, 2011). The relationship between culture and communication should therefore be reconceptualised to appreciate culture as an open-ended discursive notion dynamically constituted, rather than expressed, in interaction (Mendoza, Halualani, \& Drzewiecka, 2002; Piller, 2011).

\section{Ethnomethodological perspective on sharing cultural knowledge}

The ethnomethodological stance (e.g. Garfinkel, 1984) taken in this study challenges the traditional treatment of concepts such as culture and knowledge associated with it as variables or social facts that shape people's communication by proposing that it is in and through communication that people collaboratively produce culture and cultural knowing. Communication is understood here as a publicly available interactional process unfolding between persons (Baxter \& Braithwaite, 2008). A fundamental assumption is that communication is action, i.e. when someone says something they are actually enacting social life rather than merely transmitting information or making meaning (Mandelbaum, 2008). Communication is structured in that action consists of stable, routine-like and orderly practices. This methodical character of interactional practices is the central mechanism for the accomplishment of social order (ten Have, 2004). Furthermore, communication is seen as locally organised, with attention paid to the situated and demonstrably relevant interactional steps that participants take at the particular moment of their encounter thus producing and enacting the context (Francis \& Hester, 2004).

Cultural knowledge is taken here to denote experiences, beliefs, interpretations, routines, skills and information related to location-specific group-based meanings, symbols and practices (see also Collier \& Thomas, 1988). In accordance with the ethnomethodological perspective, I refrain from theoretically problematising the concept of culture and instead approach it empirically as a members' phenomenon. I explore how any kind of knowing about local group-based meanings, symbols and practices is made relevant, and therefore 'done' in interaction by the participants themselves.

Interest in cultural knowledge as made visible in the unfolding interactional process ties in with the idea of exploring knowledge as it is shared - recognised, accessed and distributed - rather than possessed or experienced as an internal cognitive construct.

Knowledge sharing occurs in situations where there is a knowledge gap, i.e. one of the participants comes to be categorised as more knowledgeable at the given moment of the 
unfolding conversation, and his or her specific knowledge is identified and accessed to address an issue that has emerged in interaction (Sole \& Edmondson, 2002). Cultural knowledge sharing can thus be systematically explored by analysing interactional episodes where the participants make visible their assumptions about the asymmetries in their cultural knowing through introducing categorisation as 'cultural knower' and 'not knower' for each other.

Such categorisation process can be approached with the tools of MCA (e.g. Sacks, 1986; see also e.g. Lepper, 2000; Silverman, 1998). As a form of ethnomethodological inquiry, MCA is dedicated to explicating the ordinary, practical and commonsensical reasoning that people apply as they categorise themselves and others as different kinds of members of society, and how they use this categorisation in mutually recognisable ways as an interactional resource. MCA starts with a premise that persons can be classified with a number of different labels, termed membership categories, rendering them as being of some kind. Membership categories are inference-rich because there are specific normative expectations about their characteristics, or predicates, attached to them. These predicates entail behaviours (or category-bound activities), rights, responsibilities, values, social ties and distinct knowledge. 'Cultural knower' is a membership category describing someone who has specific cultural and linguistic expertise and competences. An incumbent of this category could be assumed to speak the language fluently or be expected to help out in situations when knowledge of some 'basic cultural facts' is needed.

As the interaction develops, the participants may select and make salient specific membership categories for themselves and the others. One way of introducing categorisation is through naming of the category. Categorisation may also be accomplished by an inference drawn from a reference to, or performance of, the category's predicate (Busch, 2010), such as when a participant is asked to or offers to act as a translator. There are multiple correct membership categories that persons in interaction can use to describe one another. Contrary to mainstream intercultural communication research that treats cultural difference as a constant interactional feature in encounters between persons with different cultural backgrounds, researchers working from ethnomethodological perspectives have been able to demonstrate that interactants may only sometimes categorise each other as culturally different, thus making their interaction momentarily intercultural (e.g. Bolden, 2014).

In specific interactional situations some membership categories may be used and heard as commonsensically 'going together' to form larger collections, called membership categorisation devices. These can take the shape of standardised relational pairs which are pairs of categories whose complementary predicates bind them together with mutual rights and obligations. 'Cultural knower - not knower' is such a category collection built around the unequal distribution of cultural knowledge. It is talked into being as the potential asymmetry in the participants' cultural knowledge is made visible and consequential for the interaction. Since 'cultural knower - not knower' belong together as a standardised relational pair, deployment of either category in the unfolding interaction makes the other one discursively relevant. By way of illustration, when one of the participants enacts her lack of expertise vis-à-vis the other by requesting help to resolve a language-based problem, she assumes the membership category of 'cultural not knower' simultaneously nominating the other as 'cultural knower', thereby mobilising the standardised relational pair 'cultural knower - not knower'.

This study is guided by the following research question: How do the team members share cultural knowledge in their unfolding chat conversations through mobilising category collections 'cultural knower - not knower'? 


\section{Research setting}

\section{Participants}

This study draws on records of interactions of a four-member team embedded in a Finnish organisation, and dispersed in Finland and Russia. The team's main responsibility was to promote the internationalisation of Finnish small and medium-sized enterprises onto Russian markets. Once approached by a Finnish client company, they worked with them to prepare and guide them as they entered Russia. This entailed such activities as conducting market research, translating promotional materials, approaching possible Russian partners, organising and facilitating business negotiations between the two parties (anything from handling travel arrangements, through booking locations, to interpreting). The team also organised and participated in other networking events and projects that brought together Finnish and Russian businesses and other stakeholders. Needless to say, sharing cultural knowledge was potentially highly relevant in the team's interactions.

'Anu' and 'Elina' were co-located in the organisation's central office in

Finland. They were native speakers of Finnish and speakers of Russian as a second language. 'Irina' and 'Galina' worked in the organisation's representative office in Russia, and spoke Russian as their first language and Finnish as their second language. Towards the end of the data gathering period, Anu joined Irina and Galina in the Russian office. The team was significantly stable; in 2013, two team members had been working together for over 15 years, with the third member having joined 8 years, and the most recent one -3 years before. Anu, Elina, Irina and Galina met face-to-face approximately once a month and relied predominantly on technology for everyday interaction, mostly email, Skype ${ }^{\mathrm{TM}}$ chat and videocalling, and Google Drive ${ }^{\mathrm{Tm}}$.

\section{Data}

The data used in this study consist of log files of the team's Skype ${ }^{\mathrm{TM}}$ chat conversations. Chatting appeared to be employed for a range of everyday team interactions such as managing and debriefing tasks, relaying information to and from other team members, other colleagues in the organisation, partners and clients, giving support and feedback, non-work related conversations, attending to problems with other communication channels and coordinating availability for interaction. The chat conversations analysed spanned approximately 6 months, from March to September 2013, and consisted of 127 pages of single-spaced text. Access was gained to interactions that had taken place months before the participants became aware of the research project, which significantly reduced concerns of researcher intervention and strengthened data reliability (Silverman, 2011). Conversations conducted between five pairs of user accounts were obtained (the two Russia-based members did not use chat to communicate with each other). Some of the chatting was conducted in Finnish (Anu - Elina, Anu - Galina, Elina - Galina), and some in both Finnish and Russian, where the participants used their respective mother tongues (Anu - Irina, Elina - Irina). For the purpose of analysis, the Russian turns were translated into Finnish by a professional translator. The English translations of the excerpts presented in this article were provided by the author.

\section{Data analysis}

MCA analysis extends beyond content analysis-style listing of categories employed in the data. It builds on a sequential analysis of situated talk to demonstrate that the activities of categorisation are seen as intelligible and consequential by the participants themselves (see 
also Schegloff, 2007; Stokoe, 2012). I first went through the data to identify interactional episodes where the team members mobilised the category collection 'cultural knower - not knower' by making one of the participants' knowledge about some location-specific groupbased meanings, symbols and practices visible and situationally relevant. The participants did not directly name these membership categories; categorisation was accomplished through references to category predicates and performances of category-bound activities (e.g. 'not knowers' seeking cultural knowledge through posing questions, 'cultural knowers' providing explanations or comments drawing on their cultural knowledge). The participants made salient knowledge related to language, organisational, institutional, social and national practices, preferences, symbols and interpretations.

In the second stage of the analysis, I paid attention to how the categorisation of 'cultural knower - not knower' was introduced, oriented to and followed upon in interaction. I noticed patterns in performances of category-bound activities (who initiated the categorisation, how and why; how it was oriented to by the other participant) as well as in references to other category predicates (concerning 'cultural knower's' responsibility to share knowledge and her implied relationship to the cultural group about which she was being knowledgeable). It appeared that the category collection 'cultural knower - not knower' was accomplished in different systematic ways. I identified four recurring collections deployed in sharing cultural knowledge: (1) 'consultation giver - recipient', (2) 'review giver - recipient', (3) 'interpretation giver - recipient', and (4) 'clarification giver - recipient'. I also identified deviant cases that I investigated to refine and strengthen the analysis (Silverman, 2011).

\section{Findings}

The category collections (1) 'consultation giver - recipient', (2) 'review giver - recipient', (3) 'interpretation giver - recipient' and (4) 'clarification giver - recipient' embodied different ways of cultural knowledge sharing. The first two collections were mobilised to share cultural knowledge with relation to managing team activities, distributing work and completing tasks. The other two were introduced as the participants attended to building shared understanding in the unfolding interaction. Table 1 presents a tabulation of the identified category collections to illustrate how frequent they were in the data corpus. 'Consultation giver - recipient' was by far the most preponderant; together with 'review giver - recipient', these task-centred category pairs were invoked to frame $77 \%$ of all interactional episodes in the data corpus where cultural knowledge was shared.

Table 1 Category collections mobilised in sharing cultural knowledge

Category collection

'Consultation giver - recipient'

'Review giver - recipient'

'Interpretation giver - recipient'

'Clarification giver - recipient'

Total

$\begin{array}{ll}\text { Number } & \text { \% } \\ 63 & 71 \\ 5 & 6 \\ 12 & 13 \\ 9 & 10 \\ 89 & 100\end{array}$

\section{'Consultation giver - recipient'}

This most frequently mobilised collection was introduced as one of the participants assumed the status of 'cultural not knower' by seeking cultural consultation from the other through issuing a request for information, advice, guidance or a favour utilising her specific cultural expertise and competencies. In such exchanges, cultural knowledge was instrumentalised as 
the consultation sought was presented as consequential for completing an organisational task. Having access to the relevant knowledge domain and being under the obligation to help resolve a task-related problem was a predicate that implicated the other's category membership as 'cultural consultant'. In the majority of cases, the other participant took steps to align herself with this description by issuing a response, or consultation, thus sharing cultural knowledge. It is noteworthy that within this category collection membership in the specific cultural group was not required for a participant to become 'cultural consultant'.

Category collection 'consultation giver - recipient' was often introduced with fairly straightforward requests to which short responses were provided. I describe these instances of knowledge sharing as exploitative in the sense that their aim was to quickly access the other's knowledge base to address a practical problem rather than develop new applications or create new solutions (see also Gupta, Smith, \& Shalley, 2006), as in the following extract:

Excerpt 1

\begin{tabular}{|c|c|c|}
\hline$[9: 07: 28]$ & Elina: & $\begin{array}{l}\text { Huomenta! } \\
\text { 'Good morning!' }\end{array}$ \\
\hline$[9: 09: 23]$ & Elina: & Mikä voisi olla otsikko [venäläisen asiakkaan] kirjeessä? \\
\hline & & 'What could be the subject line in the email to [the Russian client]?' \\
\hline$[9: 10: 09]$ & Elina: & Приглашения и просьба? \\
\hline$\cdot 11 \cdot 547$ & Galina. & 'Invitation and request?' \\
\hline .11 .04$]$ & Uanma. & $\begin{array}{l}\text { Huomenta, minusta tutuntuu etta pyynnosta ei tarvitse mainita. Kirjoita vaan } \\
\text { [событиe] }\end{array}$ \\
\hline & & $\begin{array}{l}\text { 'Good morning, I don't think you need to mention the request. Just write [the } \\
\text { event]' }\end{array}$ \\
\hline$[9: 12: 38]$ & Elina: & $\begin{array}{l}\text { OK. } \\
\text { 'OK.' }\end{array}$ \\
\hline
\end{tabular}

In this example, Elina initiates interaction with Galina and seeks her opinion on a suitable subject line in an email she is writing in Russian to a Russian client. She thus introduces the categorisation 'consultation recipient' for herself and 'consultation giver' for Galina, recognising her colleague's expertise in the Russian language and Russian business correspondence. Elina takes one more turn where she offers her own idea for a possible subject line for Galina to comment on. While she maintains the "consultation recipient consultation giver' categorisation, she also displays that she is not completely novice but has some access to the relevant knowledge domain as she uses Russian as her second language at work. In what follows, Galina aligns herself with membership category 'cultural consultant' by providing a reply where she dismisses Elina's suggestion and provides one of her own. In her brief follow up turn, Elina accepts the recommendation reconfirming Galina's superior knower position.

Also more exploratory knowledge sharing took place within this category pairing where the participant categorised as 'consultation giver' was asked more complex and often open-ended questions that prompted her to develop on her knowledge base to create new applications (see also Gupta et al., 2006). The conversation presented below took place after Anu had left Finland to work in the Russian office. Although the log file shows the interaction as taking place between Elina and Anu, it transpires from Anu's turns that Galina and Irina are in the same room with her and are actively participating in the conversation. 
[14:09:34] Anu: Galina ja Irina tekevät huomiselle esitystä naisyrittäjille ja nyt kysyivät keitä venäläisiä naisia suomalaiset tuntevat????

'Galina and Irina are preparing tomorrow's presentation for women entrepreneurs and they've just asked which famous Russian women Finns know?????

[14:09:57] Elina: alla bugatseva

'alla bugatseva'

[14:10:06] Anu: mulle ei tullut mieleen, kuin Alla Pugatsova, se tennispelaaja en edes muista nimiä 'I couldn't think of anyone else but Alla Pugatsova, that tennis player I don't even remember her name'

[14:10:21] Elina: niin se tennispelaaja...tai miehet tietää sen :)

'oh yes the tennis player... well, men will probably know her :)'

[14:10:26] Anu: Anna Ahmattova

'Anna Ahmattova'

[14:10:34] Elina: oisko presidentin vaimot

'what about presidential wives'

[14:10:46] Elina: tuota ahmatovaa ei tiedä muut ku venäjän opiskelijat

'only students of Russian know ahmattova'

[14:10:55] Elina: ja se tapettu lehdistön edustaja

'and that assassinated reporter'

[14:11:28] Elina: ja se lesbo tyttöbändi

'and that lesbian girlband'

[14:11:34] Anu: joo tuosta innostuivat

'yeah they liked that one'

[14:13:25] Elina: yleensäkin naisurheiljat tiedetään

'female athletes are usually recognised'

[14:13:58] Anu: saivat jo tarpeeksi.

'they've got enough already.'

In the opening turn, Anu gives an account of what is happening in the Russian office: Galina and Irina are preparing a presentation that they are going to give at an event for female Russian entrepreneurs. They need information about which famous Russian women are recognised in Finland. Their request is made visible as Anu reports it to Elina. By issuing the request, Irina and Galina enact their co-membership in category 'consultation recipient' and invoke a collectivity of 'consultation givers' for Anu and Elina. The request is quite complex as it requires Anu and Elina to produce knowledge about Finns' knowledge about Russian politics, history, popular events, arts etc. Indeed, Anu provides a comment on the difficulty of the task as she finishes her turn with five question marks. In what follows, Elina and Anu align themselves along the expertise lines by offering names of famous Russian women potentially known to the Finnish public. Their turns are only seconds apart, which implies that they are working on their contributions simultaneously. As celebrities are listed, Anu relays them to Galina and Irina, and reports back on their reaction. It is notable that Elina narrows down the category-bound activity of knowing the Russian female celebrities whose names are mentioned in this brainstorming session to specific subcategories of category 'Finns' ('oh yes the tennis player... well, men will probably know her :)', 'only students of Russian know ahmattova'). She therefore reflects her and Anu's knowledge of female Russian celebrities against her knowledge about what different sub-groups of the Finnish society might know. This is an example of an exploratory knowledge developing activity. It also illustrates how the national category 'Finns' initially introduced by Irina and Galina is challenged for being too broad. Also of notice in this excerpt is that there is no straightforward relationship between incumbency of 'cultural consultant' category and membership of the specific cultural group. Through displaying her knowledge about 
subgroups she is not member of (as in 'Finnish men'), Elina positions herself as an outside expert on the different segments of the Finnish society.

\section{Revoking and redefining categorisation}

In the vast majority of cases, category collection 'consultation giver - recipient' was routinely deployed. A request that recognised the other's cultural expertise triggered selfcategorisation as 'consultation recipient' and implied its pair membership category 'consultation giver' that was promptly aligned with by the other participant(s). However, I also identified instances of variation in how the category collection was deployed. The first type of variation occurred when the participant who had initially categorised herself as 'consultation recipient' revoked the categorisation by posting another turn where she cancelled the original request for help stating or demonstrating that she had been able to solve the problem herself. In the other type of variation, the participant categorised as 'cultural consultant' displayed reluctance to issue a response acknowledging the limitations to her knowing, thus redefining the boundaries of her cultural expertise (see Table 2 for tabulation). These cases confirm the earlier observation that in this category collection it was not necessary for the cultural knower to be a member of the specific cultural group. Although the sharing of cultural knowledge was constructed as instrumental and the status of 'consultation giver' entailed the responsibility to share knowledge, there was a degree of openness, and leeway for negotiation, about one's access to a specific knowledge domain. One could claim epistemic rights to a body of cultural knowledge without having insider experience of the specific cultural group; conversely, being member of the group did not automatically make one knowledgeable about all the aspects of the group's life.

Table 2 Variation within category collection 'consultation giver - recipient'

Consultation giver - recipient

Accepting categorisation

Revoking categorisation

Redefining categorisation

Total

$\begin{array}{ll}\text { Number } & \text { \% } \\ 54 & 86 \\ 7 & 11 \\ 2 & 3 \\ 63 & 100\end{array}$

The following excerpt illustrates how categorisation is both revoked and redefined. It comes after an eight-turn sequence in which categorisation 'consultation giver recipient' is routinely accomplished as Elina asks questions and Galina provides responses concerning a Russian text received from a client that Elina is translating into Finnish. A hitch occurs as Elina produces another question, this time about the meaning of an abbreviation ('OY') in the Russian text:

Excerpt 3

[10:28:32] Elina: kohta Какие контролирующие органы могут проводить проверки в ОУ и накаких основаниях?

'section Какие контролирующие органы могут проводить проверки в ОУ и на каких основаниях?'

[10:28:49] Elina: mitä tuo OY tässä kohtaa tarkoittaa?

'what does this OY mean here?'

[10:33:58] Galina: Kysyn [tekstin kirjoittajalta]

'I'll ask [the author of the text]' 


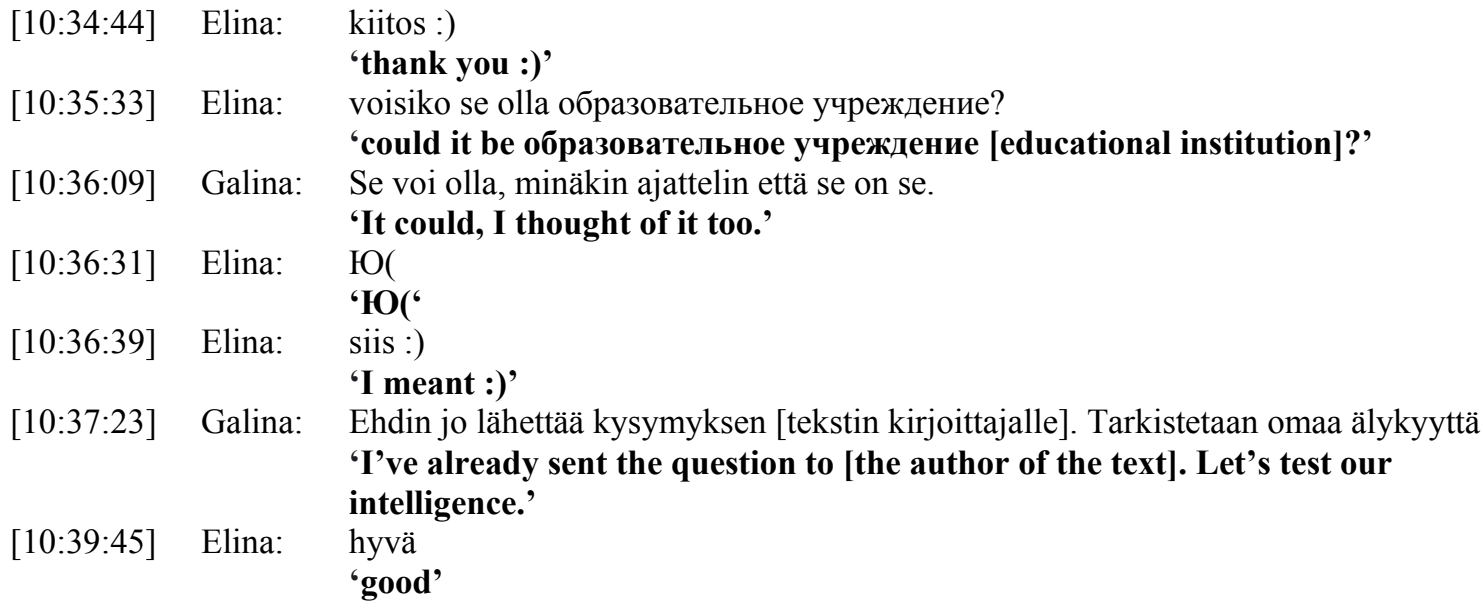

Instead of providing an answer consistently with the preceding turns, Galina responds by saying that she will turn for help to the author of the text. By refraining from issuing an answer and indicating someone else as a more expert knower, Galina acknowledges the limitations to her knowing position and redefines the boundaries of her cultural expertise. This redefinition is accepted by Elina ('thank you:)'). Although Galina is a native speaker of Russian, she is not expected to know the meaning of the abbreviation in this specific context of use. Interestingly enough, Elina takes one more turn where she herself tentatively provides an answer to her question ('could it be [...]?'). She thus revokes the earlier categorisation of herself as 'consultation recipient' by demonstrating that she, too, has access to cultural knowledge as a speaker of Russian as a second language and as someone familiar with Russian institutions, possibly due to her work experience. Her new membership category is accepted by Galina who confirms the plausibility of the solution just contributed. Moreover, Galina goes on to redefine the boundaries of her cultural expertise again by saying that she thought of the same answer. Elina and Galina have thus repositioned themselves as comembers in membership category 'cultural knower.' The new alignment is confirmed as they concur on the idea of having their mutual knowledge tested by reflecting it against the text author's forthcoming response.

\section{'Review giver - recipient'}

This was the other category collection underlying the management of team activities, distribution of work, and performance of tasks. It was introduced as one participant assumed the status of 'cultural knower', or 'review giver', by critically reviewing a course of action just produced by the other participant through the lens of some vital cultural knowledge that only she had access to and that exposed the plan as in need of correction. Similar to the previous category collection, 'review giver - recipient' did not presume membership of the cultural group to be a prerequisite for cultural knowing.

In the following extract, Galina claims 'cultural knower' status to challenge the plans that Elina has made for her:

\section{Excerpt 4}

[10:01:51] Elina: Onko sinulle kalenterissa vapaata 12.-13.6?

'Are you busy on 12.-13.6?'

[10:03:13] Galina: 13.6 on joku tilaisuus klo 17.00 [ toimistotalolla], muuta ei ole. 'On 13.6 at 17.00 there's an event [in the office building], nothing else.'

[10:03:43] Elina: ok, [henkilön nimi] tuo sinne yrityksiä ja minä ehdotan, jos sinä liityt mukaan 


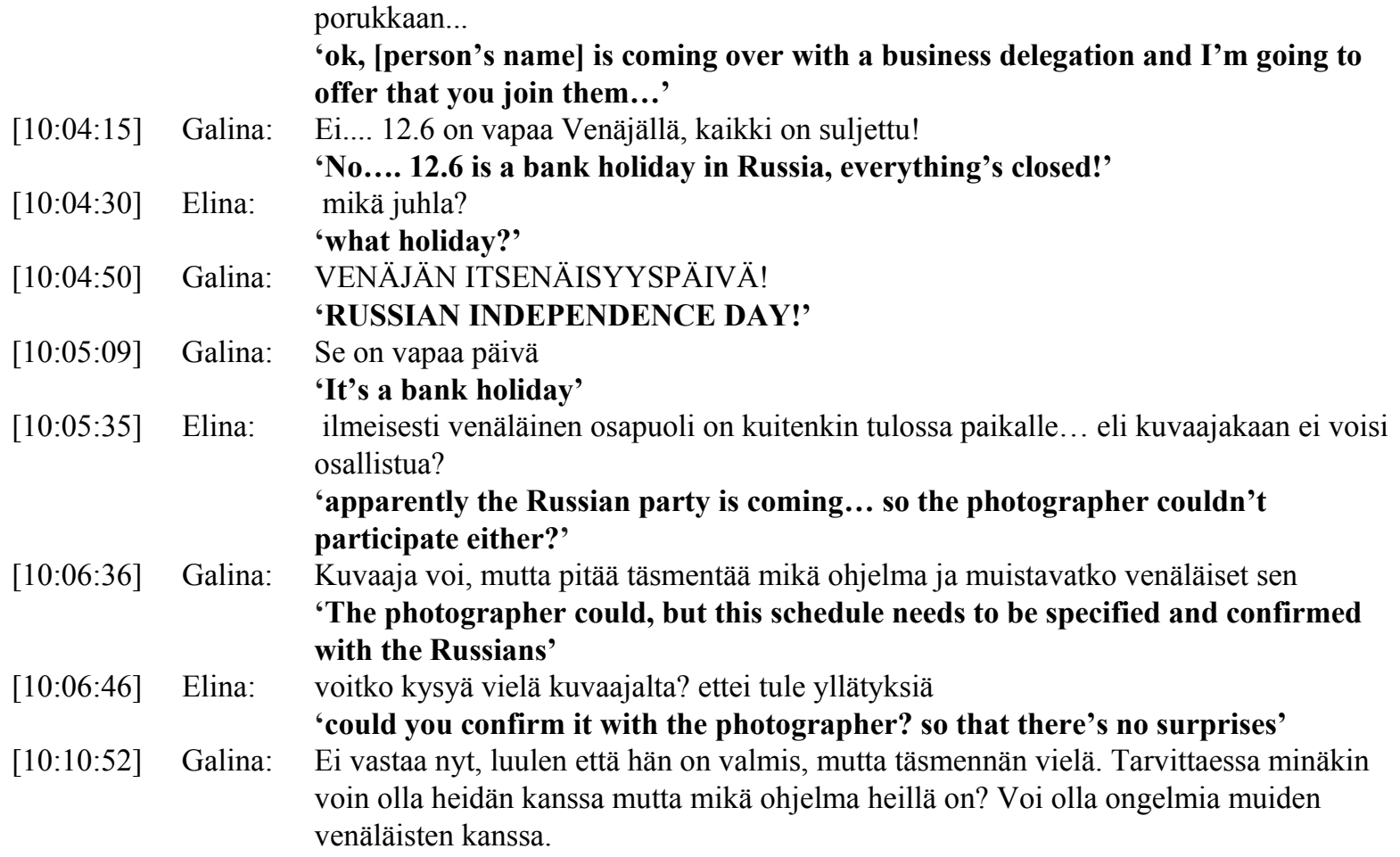
voin olla heidän kanssa mutta mikä ohjelma heillä on? Voi olla ongelmia muiden venäläisten kanssa.

'[The photographer] is not answering, I think [s]he is ready to come but I'll make sure. I could take care of them if needed but what plans do they have? There may be problems with other Russians.'

This exchange begins as Elina informs Galina that she has made plans for her to participate in hosting a business delegation from Finland. Categorisation 'review giver - recipient' is introduced as Galina shares an insight that compromises Elina's plan. The visit has been scheduled for 12 June that happens to be Russian Independence Day and a bank holiday in Russia, which is something Elina apparently did not take into consideration when planning the event. Galina appears to be upset, as evidenced in her use of punctuation ('No...,' 'everything's closed!'), and capitalisation ('RUSSIAN INDEPENDENCE DAY!'). Having had the plan critically reviewed, Elina issues questions about the implications of the overlap on people's ability to participate in the event, thus aligning herself with the status of a not knowing 'review recipient'. Galina produces two more critical comments that shed additional doubt on the feasibility of the plan ('this schedule needs to be specified and confirmed with the Russians', 'There may be problems with other Russians'). It is notable that in the last turn Galina differentiates between categories 'I' and 'other Russians'. While 'other Russians' are characterised by the predicate of possibly not being able to work on a Russian bank holiday, Galina reluctantly offers her availability. In this way, she problematises her own category membership as 'Russian', positioning herself as an unusual boundary spanning group member.

\section{'Interpretation giver - recipient'}

This category collection concerns establishing shared understanding in unfolding interaction. It was mobilised as one of the participants' 'cultural knower' status was made prominent as she spontaneously offered or was asked for an interpretation of a currently discussed issue drawing on her cultural assumptions, experiences and expectations. This way of sharing cultural knowledge was casual, occasioned by some other interaction, and it was not presented as consequential for managing teamwork and completing tasks. It also had a more informal and personal tone; categorisation as 'interpretation giver' implied one's first-hand 
experience as member of a particular cultural group. In this sense, this category pairing pivoted around imbuing situations faced by the team with personal experience from cultural groups. The surfacing of differences or making it explicit that one was embedded in a specific cultural context helped establish mutual knowledge of each other's reactions and interpretations of situations.

The following excerpt starts with categorisation 'consultation giver - recipient' as Elina asks Irina for an abridged version of a sentence in a Russian text about technology use practices in public sector organisations in Russia that Irina has authored. It is notable that although Elina and Irina are chatting in their respective mother tongues, this initial turn is the only brief moment where the bilingual character of the interaction is made salient:

\section{Excerpt 5}

[13:41:02] Elina: mitä tarkoitat Здравоохранение, наука и образование - рынки, находящиеся в самом начале информатизации 'what do you mean in Здравоохранение, наука и образование - рынки, находящиеся в самом начале информатизации'

[13:41:06] Elina: ? 6?'

[13:50:20] Irina: Это значит, что пока что врачи, учителя работают без компьютеров. Они делают записи руками, на бумаге. У них почти нет компьютеров и они не умеют на них работать.

'It means that doctors and teachers still work without computers. They take notes by hand. They don't really have computers, nor do they know how to use them.'

[13:50:58] Elina: huh huh...ja meillä on jo käytässä sähköiset reseptit :) 'wow....and we already use electronic prescriptions here :)'

[13:52:03] Irina: Спроси Ану. Она сама была свидетель, как врач все долго писал в карточку, потом выписывал рецепт. Компьютерами и не пахнет! Но кое-где уже есть, все-таки!

'Ask Anu. She witnessed herself how a doctor took a while writing things by hand in a chart, and then wrote out a prescription. No computers within sight! But they've got to be somewhere!'

[13:52:46] Elina:

(a)

. [?

[13:53:18] Elina: meillä vitsaillaan, että lääkärit eivät ehdi auttaa potilaita, kun heidän pitää käyttää tietokonetta :)

'we joke that doctors don't have enough time to treat patients as they have to use computers :)'

After Irina has confirmed her categorisation as 'consultation giver' by rendering the sentence in simpler terms, Elina claims membership in 'interpretation giver' category by producing a phatic and personal comment on the subject matter ("wow... and we already use electronic prescriptions here :)'). The way she begins her turn ('wow... and [...]') suggests that a contrasting perspective will be offered. Contrary to the previous two category collections, being categorised as 'cultural interpreter' implied one's membership or personal experience in the specific cultural group. This is evident in Elina's turn as she uses the pronouns 'we' and 'here'. Pronouns are indexicals or expressions whose meaning is in part dependent upon the features of the context of utterance (Lepper, 2000). Indexicals implicate categorisation work. Elina produces her turn as a commentary on the sentence about practices in Russian public sector organisations; it can therefore be inferred that 'we here' refers to people in 
Finland, with Elina herself incumbent of this category. By sharing a comment about practices in Finland, she reveals her interpretation and reaction to the text: coming from Finland, she is surprised by the presented practices in Russian educational and health care institutions. In reaction to this, Irina points to and recounts Anu's first-hand experience of seeing a doctor in Russia where the doctor took notes and wrote the prescription out by hand, "no computers within sight'. Relating the generalised statement to the personal experience of someone they both know supports the credibility of Irina's text and consolidates her position as a 'cultural consultant'. Since Anu is member of the same category 'people in Finland' as Elina, telling the narrative of her health care encounter in Russia also serves to indicate that Irina recognises and validates the 'Finnish interpretation' that Elina has just shared. Elina reacts to Irina's turn by issuing a token of appreciation with a 'rolling on the floor laughing' emoticon. She then provides another cultural interpretation on the subject matter by presenting a comment about people in Finland ridiculing the constraints introduced by the digitalisation of doctors' work. References to popular sayings and jokes serve as 'factual' evidence that authorises speakers' knowledge claims (Lepper, 2000). Elina shares insider knowledge about the general experience of being a patient in Finland. This comment can also be viewed as face-saving as it mitigates the polarised image of technology-related practices in Finland and Russia constructed earlier by emphasising similarities in the positioning of patients in the two countries. Both reliance technology and its lack can have a negative impact on patient care.

\section{'Clarification giver - recipient'}

This was the other category collection invoked in establishing shared understanding in unfolding interaction. Unlike category pair 'interpretation giver - recipient' where the sharing of cultural knowledge was casual and optional, clarification was necessitated by occasional breaks in immediate mutual understanding as the conversation developed. It pivoted on the mechanism of conversational repair (e.g. Silverman, 1998) through which a notion presented in one of the participant's turn was exposed as a novel culturally-signified item and its meaning was clarified to the other not knowing participant. This category collection could be introduced by the participant who was currently producing a turn as she herself displayed a presumption that some item that she had just used could be considered as problematic by the other, and provided an explanation or clarification of it. Categorisation could also be mobilised by the other participant who assumed a not knowing position by issuing a request for clarification. The mobilisation of this category collection evidences that the participants monitored own and the other's turns for potential sources of non-understanding. Categorisation as 'clarification giver' implied the given participant's personal experience in the specific cultural group. As the problem was attended to, the main activity was momentarily put on hold, and resumed once the item had been clarified.

The excerpt below starts with Elina making an announcement that she will not be available for computer-mediated interaction on the following day:

Excerpt 6

[15:51:53] Elina: Meillä on huomenna kehittämispäivä, joten olen poissa toimistolta. Minut saa kiinni puhelimella :)

'We have a development day [“kehittämispäivä"] tomorrow so I'll be away from the office. I can be contacted by phone :)'

[15:54:50] Irina: На что похож этот kehittämispäivä? Что вы там будете делать? 'What is this kehittämispäivä? What do you do there?'

[15:57:04] Elina: uutta [organisaation nimi] organisaatiota, joka tulivoimaan 1.9 :) Kehitämme palveluita, sisäisiä toimintapoja jne. 
The reason for being away from the office provided by Elina ('We have a development day ["kehittämispäivä"] tomorrow') prompts Irina to introduce category collection 'clarification giver - recipient' as she asks what a development day denotes. By using the Finnish word 'kehittämispäivä' in her otherwise Russian utterance, she briefly orients to the interaction as bilingual and indicates that the novelty of the concept may stem from her inability to formulate its Russian language counterpart. The follow up question ('What do you do there?') mirrors Elina's use of 'we' with plural 'you' but there is no indication of Irina knowing who the 'you' refers to, and therefore, who, and how, participates in development days. Elina's response confirms the category collection mobilised by Irina as she elaborates on the problematic item as 'event at the central office:' she mentions such category-bound activities as discussing services and internal procedures, and the organisation's name is given. By implication, the membership categories this collection comprises are the employees located at the central office. Since Elina is a central office employee, she has knower status about its practices. Irina, in turn, is an outsider and a not knower. Elina finishes her clarification with a 'puke' emoticon that downgrades the meaning of her utterance and indicates that the activities described should be read as a nuisance. Irina's following confirmation ('Oh, it's about that!') signals that she appreciates the clarification and that her understanding of the reasons for Elina being unavailable has been expanded. Her additional statement starting with 'anyway' terminates the category collection 'clarification giver recipient' and puts the main activity back on track.

\section{Discussion}

This article describes the systematic commonsensical ways in which members of an internationally dispersed team shared cultural knowledge in their Skype ${ }^{\mathrm{TM}}$ chat interactions through mobilising categorisation as (1) 'consultation giver - recipient', 2) 'review giver recipient', (3) 'interpretation giver - recipient' and (4) 'clarification giver - recipient'. The study offers insights into the knowledge sharing processes of one team conducted in one communication channel. Its contribution lies in the use of naturally occurring data and an inductive interaction-centred method, rendering observations that do not correspond with the theoretical frameworks that have typically informed research in the area. Clearly more studies that draw on records of naturally occurring interactions of real working life teams are needed to expand our understanding of knowledge processes in internationally dispersed collaboration.

The dominant image of cultural team diversity presumes that asymmetries in cultural and linguistic knowledge are an omnipresent feature of the interactional backdrop. The data discussed in the study show the contingent, moment-by-moment and collaborative character of knowledge processes. Although sharing cultural knowledge was important for the completion of tasks and maintenance of mutual understanding, my participants did not always orient to possible differences in their cultural knowing, and did not automatically construe their chat conversations as intercultural. The chat medium was used to accomplish a variety of activities and, depending on the local context, category collections that mobilised cultural knowledge gaps were occasionally talked into (and out of) being. It is remarkable that even when the team members chatted in their respective mother tongues, they often did not make their different linguistic memberships visibly relevant. The team's language 
practices that defy the traditional idea of distinct speech communities could be explored in more depth with concepts such as metrolingualism, multilanguaging and lingua receptiva (e.g. Lüdi, 2013; Otsuji \& Pennycook, 2010).

The findings do not support the prevalent 'double-edged sword' understanding of the relationship between cultural diversity and team interactions. The chat conversations I analysed were neither fraught with cultural misunderstandings and conflict, nor brimming with cultural synergy and innovation. Reliance on communication technologies has been blamed for constraining spontaneous informal interactions among team members (e.g. Berry, 2011; Sole \& Edmondson, 2002). Researchers have claimed that members of dispersed teams fail to share knowledge about their local situations (e.g. Cramton, 2001) and that they may intentionally refrain from interacting with distant team members whom they perceive to be culturally different (e.g. Cramton \& Hinds, 2005). The participants of my study, however, displayed interactional commitment and concern for monitoring mutual understanding and, where necessary, made active efforts to build awareness of one another's perspective through mobilising category collections 'interpretation giver - recipient' and 'clarification giver recipient'. The relative infrequency of these category pairings should be considered in the light of the fact that the team shared a working history and oriented towards the future together; they had developed fairly close interpersonal bonds and a store of common knowledge to fall back on - all through mostly technology-mediated interaction.

The most popular category collection 'consultation giver - recipient' was mobilised to quickly access the other's knowledge base to deal with a task-related issue. The team members appeared to know who knew what and had established routines for knowledge sharing enabling the efficient division and accomplishment of tasks. I found no examples of situations where the participants occupying different cultural knowing positions would disclose and creatively combine their respective knowledge domains in innovative or synergistic ways to create new alternatives and perspectives (see also Gupta et al., 2006). While the chat medium may privilege specific knowledge-sharing practices over others (see also Erhardt \& Gibbs, 2008), this observation is nevertheless significant since the team's activities explicitly concerned cultural exchange. The finding contradicts the popular theoretical expectations about knowledge work in internationally dispersed teams, encouraging a thought that the lived reality of such collaboration may be more mundane than it is often assumed. Cultural synergy, innovation and intercultural learning in organisational contexts are knowledge construction processes that require more systematic, qualitative and situated, empirical investigations.

Existing research into internationally distributed teaming has tended to presume that there is a 'natural' and enduring connection between team members' national/ethnic background and their cultural knowledge. In my study, the participants often made nationallevel practices, symbols and meanings relevant. However, these categories did not exist on their own (see also Dervin, 2014). For instance, patient care practices in Russia or Finland are affected by access to technological and economic resources. Cultural knowledge did not appear to have an exclusive relationship with nation/ethnicity but was fashioned also with reference to linguistic proficiency, and business, organisational, social or institutional contexts. Just as nation was made salient, it was also problematised as in the excerpt where Elina matches familiarity with specific famous Russian women to different subgroups of the Finnish society. Furthermore, the team allowed flexibility, permeable boundaries and joint access to cultural knowledge domains. The participants' cultural knowing did not have a straightforward relationship to, and it extended beyond, their national backgrounds. This observation illustrates the fallacy of the traditional thinking that ties people's cultural knowing to physical place. My participants drew their epistemic resources from their multiple group memberships, educational backgrounds, travel, media consumption, and their shared 
experience of internationalisation work enabled through modern communication technologies. Taken together, the team's flexible accomplishments of cultural knowing evidence their ability to jointly build and maintain their shared reality through both 'being diverse' and 'being similar'. This can be regarded as a highly important form of the team's shared communication competence (see also Stokoe, 2010).

\section{Acknowledgements}

This work was supported by the Academy of Finland within the research project Interpersonal Communication Competence in Virtual Teams [138186], and the Finnish Cultural Foundation. The present article is part of the author's doctoral dissertation under preparation supervised by Professor Maarit Valo at the Department of Communication, University of Jyväskylä. The author wishes to express her gratitude to Dr Margarethe Olbertz-Siitonen for her support and invaluable comments on ethnomethodological inquiry.

\section{References}

Baba, M.L., Gluesing, J., Ratner, H., \& Wagner, K.H. (2004). The contexts of knowing: Natural history of a globally distributed team. Journal of Organizational Behavior, 25. 547-587.

Baxter, L.A., \& Braithwaite, D. O. (2008). Discourse/interaction-centered theories of interpersonal communication. In L.A. Baxter \& D.O. Braithwaite (Eds.), Engaging theories in interpersonal communication: Multiple perspectives (pp. 145-148). Los Angeles: Sage.

Berg, R. (2012). The anonymity factor in making multicultural teams work: Virtual and real teams. Business Communication Quarterly, 75(4), 404-424.

Berry, G. (2011). Enhancing effectiveness on virtual teams. Journal of Business Communication, 48(2), 186-206.

Bolden, G. (2014). Negotiating understanding in "intercultural moments" in immigrant family interactions. Communication Monographs, 81(2), 208-238.

Breidenbach, J., \& Nyíri, P. (2009). Seeing culture everywhere: From genocide to consumer habits. Seattle: University of Washington Press.

Busch, D. (2010). Shopping in hospitality: Situational constructions of customer-vendor relationships among shopping tourists at a bazaar on the German-Polish border. Language and Intercultural Communication, 10(1), 72-89.

Chrobot-Mason, D., Ruderman, M.N., Nishii, L.H. (2013). Leadership in a diverse workplace. In Q.M. Roberson (Ed.), The Oxford handbook of diversity and work (pp.315-340). New York, Oxford: Oxford University Press.

Connaughton, S. L., \& Shuffler, M. (2007). Multinational and multicultural distributed teams: A review and future agenda. Small Group Research, 38(3), 387-412.

Collier, M. J. \& Thomas, M. (1988). Identity in intercultural communication: An interpretive perspective. In Y. Kim \& W. Gudykunst (Eds.), Theories of intercultural communication: International and intercultural communication annual, 12, 99-120. Newbury Park, CA: Sage.

Cramton, C. D. (2001). The mutual knowledge problem and its consequences for dispersed collaboration. Organization Science, 12(3), 346-371.

Cramton \& Hinds (2005). Subgroup dynamics in internationally distributed teams: Ethnocentrism or cross-national learning? Research in Organizational Behavior, 26, 231-263. 
Dervin, F. (2014). Exploring "new" interculturality online. Language and Intercultural Communication, 14(2), 191-206.

Erhardt, N., \& Gibbs, J. (2008). Dynamics of team-based knowledge work: Exploring the link between knowledge processes and media use. Paper presented at the National Communication Association's annual convention, 21-24 November, San Diego, California.

Francis, D., \& Hester, S. (2004). An invitation to ethnomethodology: Language, society and interaction. London: Sage.

Garfinkel, H. (1984). Studies in ethnomethodology. Cambridge: Polity Press.

Gibbs, J., Nekrassova, D., Grushina, S., \& Wahab, S. (2008). Reconceptualizing virtual teaming from a constitutive perspective: Review, redirection, and research agenda. Communication Yearbook, 32, 187-229.

Gibson, C. B., \& Gibbs, J. L. (2006). Unpacking the concept of virtuality: The effects of geographic dispersion, electronic dependence, dynamic structure, and national diversity on team innovation. Administrative Science Quarterly, 51, 451-495.

Gupta, A., Smith, K., \& Shalley, C. (2006). The interplay between exploration and exploitation. Academy of Management Journal, 49(4), 693-706.

Hinds, P., \& Mortensen, M. (2005). Understanding conflict in geographically distributed teams: The moderating effects of shared identity, shared context, and spontaneous communication. Organization Science, 16(3), 290-307.

Holliday, A. (2011). Intercultural communication and ideology. Thousand Oaks: Sage.

Hunsinger, R. P. (2006). Culture and cultural identity in intercultural technical communication. Technical Communication Quarterly, 15(1), 31-48.

Lepper, G. (2000). Categories in text and talk. London: Sage.

Lüdi, G. (2013). Receptive multilingualism as a strategy for sharing mutual linguistic resources in the workplace in a Swiss context. International Journal of Multilingualism, 10(2), 140-158.

Mandelbaum, J. (2008). Conversation analysis theory. In L.A. Baxter \& D.O. Braithwaite (Eds.), Engaging theories in interpersonal communication: Multiple perspectives (pp. 175-188). Los Angeles: Sage.

Mendoza, S. L., Halualani, R. T., \& Drzewiecka, J. A. (2002). Moving the discourse on identities in intercultural communication: Structure, culture, and resignifications. Communication Quarterly, 50(3\&4), 312-327.

Otsuji, E., \& Pennycook, A. (2010). Metrolingualism: Fixity, fluidity and language in flux. International Journal of Multilingualism, 7(3), 240-254.

Piller, I. (2011). Intercultural communication: A critical introduction. Edinburgh: Edinburgh University Press.

Rubdy, R., \& Alsagoff, L. (2014). The cultural dynamics of globalisation: Problematising hybridity. In R. Rubdy \& L. Alsagoff (Eds.), The global-local interface and hybridity: Exploring language and identity (pp. 1-14). Bristol: Multilingual Matters.

Sacks, H. (1986). On the analyzability of stories by children. In J. Gumperz \& D.

Hymes (Eds.), Directions in sociolinguistics: The ethnography of communication (pp. 325-345). Oxford: Blackwell.

Sarker, S. (2005). Knowledge transfer and collaboration in distributed U.S.-Thai teams. Journal of Computer-Mediated Communication, 10(4).

Schegloff, E. (2007). A tutorial on membership categorization. Journal of Pragmatics, 39, $462-482$. 
Scott, M. (2013). "Communicate through the roof": A case study analysis of the communicative rules and resources of an effective global virtual team. Communication Quarterly, 61(3), 301-318.

Silverman, D. (2011). Interpreting qualitative data: A guide to the principles of qualitative research ( $4^{\text {th }}$ ed.). Los Angeles: Sage.

Silverman, D. (1998). Harvey Sacks: Social science and conversation analysis. Cambridge: Polity Press.

Sole, D., \& Edmondson, A. (2002). Situated knowledge and learning in dispersed teams. British Journal of Management, 13(S2), S17-S34.

Stahl, G. K., Maznevski, M. L. Voight, A., \& Jonsen K. (2010). Unraveling the effects of cultural diversity in teams: A meta-analysis of research on multicultural work groups. Journal of International Business Studies, 41, 690-709.

Stokoe, E. (2012). Moving forward with membership categorization analysis: Methods for systematic analysis. Discourse Studies, 14(3), 277-303.

Stokoe, E. (2010). "I'm not gonna hit a lady": Conversation analysis, membership categorization and men's denials of violence towards women. Discourse \& Society, 21(1), 59-82.

ten Have, P. (2004). Understanding qualitative research and ethnomethodology. London: Sage.

Zakaria, N., Amelinckx, A., \& Wilemon, D. (2004). Working together apart? Building a knowledge sharing culture for global virtual teams. Creativity and Innovation Management, 13, 15-29. 